\title{
Using hand grip strength to detect slow walking speed in older adults: the Yilan study
}

Yen-Huai Lin ${ }^{1,2}$, Hsi-Chung Chen ${ }^{3}$, Nai-Wei Hsu $2,4,56^{*}$ and Pesus Chou ${ }^{4}$

\begin{abstract}
Background: Walking speed is an important health indicator in older adults, although its measurement can be challenging because of the functional decline due to aging and limited environment. The aim of this study was to examine whether hand grip strength can be a useful proxy for detecting slow walking speed in this population.

Methods: A cross-sectional study was conducted using the cohort from the Yilan Study in Taiwan. Communitydwelling older adults aged 65 years and older were included. Slow walking speed was defined as a 6-meter walking speed $<1.0 \mathrm{~m} / \mathrm{s}$, according to the 2019 Asian Working Group for Sarcopenia diagnostic criteria. Stepwise multiple linear regression was used to determine the most significant variables associated with walking speed. Receiver operating characteristic analysis was used to determine the optimal cutoff values for hand grip strength in detecting slow walking speed.
\end{abstract}

Results: A total of 301 participants with an average age of $73.9 \pm 6.8$ years were included; $55.1 \%$ participants were women. In stepwise multiple linear regression analysis that included various variables, hand grip strength was found to be the most explainable factor associated with walking speed among all participants and among participants of each sex. The optimal cutoff values for hand grip strength in the detection of slow walking speed were $19.73 \mathrm{~kg}$ for all participants (sensitivity: $55 \%$, specificity: $83 \%$, area under the curve: 0.74 , accuracy: $66.9 \%$ ), $35.10 \mathrm{~kg}$ for men (sensitivity: $92 \%$, specificity: $42 \%$, area under the curve: 0.70 , accuracy: $66.4 \%$ ), and $17.93 \mathrm{~kg}$ for women (sensitivity: $62 \%$, specificity: $80 \%$, area under the curve: 0.76 , accuracy: $67.9 \%)$.

Conclusions: Hand grip strength was found to be a useful proxy for the identification of slow walking speed in older adults.

Keywords: Hand grip strength, Walking speed, Yilan study

\section{Introduction}

The global trend of population aging is increasing dramatically, and frailty has become a vital issue owing to its increasing prevalence and adverse impact on older adults. Frailty is not only associated with hospitalization

\footnotetext{
* Correspondence: davidnwh@ms28.hinet.net

${ }^{2}$ Department of Medicine, School of Medicine, National Yang Ming Chiao Tung University, Taipei, Taiwan

${ }^{4}$ Community Medicine Research Center, National Yang Ming Chiao Tung University, Taipei, Taiwan

Full list of author information is available at the end of the article
}

and institutionalization $[1,2]$ but it is also a predictor of mortality [1,3]. Thus, the evaluation of frailty among community-dwelling older adults is essential for public health [4].

In the definition of frailty, hand grip strength and walking speed are the core criteria [5]. Both hand grip strength and gait are altered with aging and reflect the severity of sarcopenia associated with frailty. Compared with hand grip strength, walking speed is specifically used to investigate the decline in mobility [6]. Converging evidence

C C The Author(s). 2021 Open Access This article is licensed under a Creative Commons Attribution 4.0 International License, which permits use, sharing, adaptation, distribution and reproduction in any medium or format, as long as you give appropriate credit to the original author(s) and the source, provide a link to the Creative Commons licence, and indicate if changes were made. The images or other third party material in this article are included in the article's Creative Commons licence, unless indicated otherwise in a credit line to the material. If material is not included in the article's Creative Commons licence and your intended use is not permitted by statutory regulation or exceeds the permitted use, you will need to obtain permission directly from the copyright holder. To view a copy of this licence, visit http://creativecommons.org/licenses/by/4.0/ The Creative Commons Public Domain Dedication waiver (http://creativecommons.org/publicdomain/zero/1.0/) applies to the data made available in this article, unless otherwise stated in a credit line to the data. 
supports the use of walking speed as a component of frailty assessment [7-9]. Therefore, a walking speed of $0.8 \mathrm{~m} / \mathrm{s}$ is chosen as the cutoff in the European consensus definition of sarcopenia, which is also considered a slow walking speed [10]. There are multiple walking speed tests comprising various distances, including 8,10 , and 15 feet and $3,4,5,6,11$, and $30 \mathrm{~m}[11,12]$. Among these, the 4and 6-meter walking speed tests are the most commonly recommended [10, 13]. However, the living environment and decreased cognitive and physical abilities of older adults tend to compromise the feasibility of measuring walking speed, particularly in frail individuals. Therefore, it is important to develop a proxy for the identification of slow walking speed for assessing frailty.

Hand grip strength is another major component in frailty assessment; it is a useful indicator of the current health status. For example, hand grip strength is related to lower bone mineral density or osteoporosis [14, 15], malnutrition [16], cognitive impairment [17], multimorbidity [18], depression [19], frailty [4], and long sleep duration [20]. Thus, owing to the high clinical relevance, availability, and accessibility of measuring hand grip strength, it is intuitive to consider the use of hand grip strength as a proxy for the detection of slow walking speed [21-25].

In the literature, hand grip strength has been proposed as a method to identify slow walking speed $(<0.8 \mathrm{~m} / \mathrm{s})$, although the cutoff values varied according to sex and race [21-25]. In a large, diverse sample of older adults, a grip strength of less than $16 \mathrm{~kg}$ in women and $26 \mathrm{~kg}$ in men was associated with slow walking speed [21]. The Health and Retirement Study found the hand grip strength cutoff values for the detection of slow walking speed to be similar for black and white men $(<35 \mathrm{~kg})$, but higher for black women than for white women (< $31 \mathrm{~kg}$ vs. $<22 \mathrm{~kg}$ ) [23]. In a Turkish study that included 406 older adults, a hand grip strength cutoff value of $22 \mathrm{~kg}$ for women had a sensitivity of $76.9 \%$ and specificity of $62.5 \%$, while in men, a cutoff value of $32 \mathrm{~kg}$ had a sensitivity of $80.5 \%$ and specificity of $76.2 \%$ [22]. However, participants in this study were recruited among patients visiting an outpatient clinic and were not community-dwelling older adults, which limits its generalizability. In the InCHIANTI study, a hand grip strength cutoff value of $19.3 \mathrm{~kg}$ had an area under the curve (AUC) of 0.90 in women, while a cutoff value of $30.3 \mathrm{~kg}$ had an AUC of 0.90 in men [24]. However, this study included participants from the general population, with ages ranging from 20 to 102 years, and not from the older adult population. In a cross-sectional study that included 5783 older adults, a hand grip strength cutoff value of $21 \mathrm{~kg}$ for women had a sensitivity of $58.6 \%$, a specificity of $72.9 \%$ and an AUC of 0.83 , whereas a cutoff value of $32 \mathrm{~kg}$ for men had a sensitivity of $49.1 \%$, a specificity of $79.8 \%$, and an AUC of 0.82 [25]. However, this study included a non-Asian population. To the best of our knowledge, only a few studies have reported cutoff values for hand grip strength to detect slow walking speed among community-dwelling or older Asian adults [22].

Furthermore, in 2019, the Asian Working Group for Sarcopenia (AWGS) updated the diagnostic cutoff value of slow walking speed from $\leq 0.8$ to $<1.0 \mathrm{~m} / \mathrm{s}$ [13]. It is unknown whether hand grip strength is the best proxy for the detection of slow walking speed. Hence, there is a need to examine the magnitude of association between hand grip strength and various potential candidate variables with walking speed. In addition, if appropriate, it is also necessary to determine the optimal cutoff value for hand grip strength based on the most recent definition of slow walking speed.

Therefore, the primary aim of this study was to determine whether hand grip strength is the most optimal explainable correlate for walking speed in Asian community-dwelling older adults compared with various candidate variables and the extent to which hand grip strength correlated with walking speed. After confirming this, the secondary aim of this study was to determine the optimal cutoff values for hand grip strength to detect slow walking speed according to the updated criteria of the AWGS in 2019.

\section{Methods \\ Participants}

This cross-sectional study was part of the Yilan Study, an integrative community-based health survey conducted from 2012 to 2016 in Taiwan. The study design has been described in detail elsewhere [26]. Briefly, residents of Yilan City aged 65 years and above were randomly recruited for participation. Well-trained project assistants conducted face-to-face interviews with the participants at their homes. To identify the potential variable and compare their association with walking speed in contrast to hand grip strength, this study included not only sociodemographic characteristics but also smoking and drinking status, lifestyle, physical and mental conditions, and anthropometric measurements in the analysis. The inclusion criteria were the ability to complete the interview and perform the hand grip strength test and 6-meter walking test. We excluded participants who could not complete the interview, were unable to cooperate with the anthropometric measurements because of physical and cognitive disability, or could not perform the 6-meter walking test because of the limited living environment at their homes. Finally, a total of 301 participants (mean age: 74.3 years; range: 65-99 years), who provided written informed consent, were included. This study was approved by the institutional review board of NYMUH (IRB No. 2011A016). 
Measurements of hand grip strength and muscle mass Hand grip strength $(\mathrm{kg})$ was measured using a digital hand dynamometer (EH101; Camry ${ }^{\circ}$, Guangdong Province, China). The grip strength of each hand was assessed twice; the maximal value of each hand was averaged as the final estimate of hand grip strength for analysis. The muscle masses of the trunk, upper and lower extremities were measured using bioelectrical impedance analysis (InnerScan V, TANITA ${ }^{\bullet}$ BC601, Japan).

\section{Slow walking speed}

Participants were requested to walk for $6 \mathrm{~m}$ at their usual pace, with additional 2-meter sections for acceleration and deceleration to ensure a consistent walking speed over the measured distance. Slow walking speed was defined as a walking speed $<1.0 \mathrm{~m} / \mathrm{s}$, as per the 2019 recommendations of the AWGS [13].

\section{Other covariates}

Data on sociodemographic characteristics including age ( $\geq 75$ vs. $<75$ years), sex, body mass index, education status (junior and above vs. primary), and living status (living alone vs. living with others) were obtained. In addition, data on smoking history, drinking status, and frequency of exercise ( $<3$ vs. $\geq 3$ times per week) were recorded. With respect to chronic medical morbidities, self-reported data on diabetes mellitus, hypertension, heart disease, hyperlipidemia, stroke, cancer, gout, respiratory diseases, lower limb arthritis, and falls were collected. Medical diseases were recorded only for participants who reported being diagnosed with a disease

Table 1 Six-meter walking speed by sociodemographic and lifestyle of participants ( $n=301$ )

\begin{tabular}{|c|c|c|c|}
\hline & $\begin{array}{l}\text { Total } \\
\text { n (\%) }\end{array}$ & $\begin{array}{l}\text { 6-Meter Walking Speed (m/sec) } \\
\text { Mean (SD) }\end{array}$ & $\begin{array}{l}p \text {-value } \\
\text { for t- } \\
\text { test/ } \\
\text { ANOVA }\end{array}$ \\
\hline \multicolumn{4}{|l|}{ Age (years) } \\
\hline$\geq 75$ & $127(42.2)$ & $0.79(0.29)$ & \multirow[t]{2}{*}{$<0.001$} \\
\hline$<75$ & $174(57.8)$ & $1.03(0.31)$ & \\
\hline \multicolumn{4}{|l|}{ Sex } \\
\hline Women & $166(55.1)$ & $0.87(0.33)$ & \multirow[t]{2}{*}{$<0.001$} \\
\hline Men & $135(44.9)$ & $1.00(0.29)$ & \\
\hline \multicolumn{4}{|c|}{ Body mass index $\left(\mathrm{kg} / \mathrm{m}^{2}\right)^{a}$} \\
\hline $18.5-23.9$ & $130(43.2)$ & $0.98(0.30)$ & \multirow[t]{3}{*}{0.078} \\
\hline$<18.5$ & $11(3.7)$ & $0.91(0.22)$ & \\
\hline$\geq 24.0$ & $158(52.5)$ & $0.89(0.33)$ & \\
\hline \multicolumn{4}{|l|}{ Education status } \\
\hline Junior and above & $180(59.8)$ & $0.99(0.30)$ & \multirow[t]{2}{*}{0.001} \\
\hline Primary & $121(40.2)$ & $0.84(0.33)$ & \\
\hline \multicolumn{4}{|l|}{ Living status } \\
\hline With others & $280(93.0)$ & $0.93(0.32)$ & \multirow[t]{2}{*}{0.647} \\
\hline Alone & $21(7.0)$ & $0.90(0.26)$ & \\
\hline \multicolumn{4}{|l|}{ Smoking status } \\
\hline Non-smoker & $246(81.7)$ & $0.92(0.33)$ & \multirow[t]{3}{*}{0.115} \\
\hline Ex-smoker & $39(13.0)$ & $0.94(0.30)$ & \\
\hline Current-smoker & $16(5.3)$ & $1.09(0.20)$ & \\
\hline \multicolumn{4}{|l|}{ Drinking status } \\
\hline Non-drinker & $248(82.4)$ & $0.91(0.33)$ & \multirow[t]{3}{*}{0.06} \\
\hline Ex-drinker & $10(3.3)$ & $0.99(0.24)$ & \\
\hline Current-drinker & $43(14.3)$ & $1.03(0.25)$ & \\
\hline \multicolumn{4}{|l|}{ Frequency of exercise ${ }^{a}$} \\
\hline$<3$ / week & $54(17.9)$ & $0.79(0.32)$ & \multirow[t]{2}{*}{$<0.001$} \\
\hline$\geq 3 /$ week & $244(81.1)$ & $0.96(0.31)$ & \\
\hline
\end{tabular}

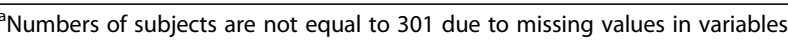


and treated for it. The Hospital Anxiety and Depression Scale was used to assess symptoms of depression and anxiety in all participants. The optimal cutoff points for anxiety and depression are 3 and 6 on the respective subscales [27].

\section{Statistical analysis}

The independent $t$-test and one-way analysis of variance were used to examine the factors associated with 6meter walking speed. Pearson's correlation coefficient was calculated to investigate the relationship between walking speed, anthropometric measurements, and hand grip strength. Significant variables were included in the stepwise multiple linear regression analysis to determine the variables that significantly correlated with walking speed. The Shapiro-Wilk test was used to confirm the normal distribution of unstandardized residuals $(p>$ 0.05). Receiver operating characteristic (ROC) curves and the corresponding AUC were used to evaluate how well hand grip strength was associated with slow walking speed. Youden's index (sensitivity + specificity -1 ) from the ROC curve was used to determine cutoff values. We also compared the performance of hand grip strength as a single proxy with the predicted model using stepwise multiple linear regression to detect slow walking speed. Missing values were regarded as missing completely at random; thus, available-case analyses were implemented to handle missing data. All reported $p$-values were two sided, and the statistical significance level was set at $p<$ 0.05. Analyses were performed using SPSS for Windows (version 19.0; IBM Corp., Armonk, NY, USA).

\section{Results}

Table 1 presents the socio-demographic characteristics and lifestyle data associated with the 6-meter walking speed. Participants who were older, were women, had a low education level, and did not exercise regularly had a slower walking speed than other participants. Table 2 presents the physical and mental conditions and their associations with 6-meter walking speed. Participants with diabetes, hypertension, heart disease, stroke, lower limb arthritis, and depression had a slower walking speed than other participants.

Table 3 presents the correlations between walking speed, anthropometric measurements, and hand grip strength. Walking speed was associated with age, height, weight, hand grip strength, and muscle mass. Moreover, hand grip strength was significantly associated with total body, trunk, and upper and lower limb muscle mass.

The significant variables shown in Tables 1, 2 and 3 were included in stepwise multiple linear regression. To avoid collinearity, only the muscle mass data of the upper and lower limbs were included in the analysis. Table 4 shows the stepwise multiple linear regression
Table 2 Six-meter walking speed by physical and mental related comorbid conditions $(n=301)$

\begin{tabular}{|c|c|c|c|}
\hline & $\begin{array}{l}\text { Total } \\
\text { n (\%) }\end{array}$ & $\begin{array}{l}\text { 6-meter walking speed (m/sec) } \\
\text { Mean (SD) }\end{array}$ & $\begin{array}{l}p \text {-value } \\
\text { for t- } \\
\text { test/ } \\
\text { ANOVA }\end{array}$ \\
\hline \multicolumn{4}{|c|}{ Physical-related comorbid conditions } \\
\hline \multicolumn{4}{|c|}{ Diabetes mellitus } \\
\hline Yes & $61(20.3)$ & $0.85(0.33)$ & 0.029 \\
\hline No & $240(79.7)$ & $0.95(0.32)$ & \\
\hline \multicolumn{4}{|c|}{ Hypertension } \\
\hline Yes & $145(48.2)$ & $0.87(0.34)$ & 0.004 \\
\hline No & $156(51.8)$ & $0.98(0.29)$ & \\
\hline \multicolumn{4}{|c|}{ Heart diseases } \\
\hline Yes & $84(27.9)$ & $0.84(0.32)$ & 0.004 \\
\hline No & $217(72.1)$ & $0.96(0.32)$ & \\
\hline \multicolumn{4}{|c|}{ Hyperlipidemia } \\
\hline Yes & $88(29.2)$ & $0.93(0.37)$ & 0.860 \\
\hline No & $213(70.8)$ & $0.93(0.30)$ & \\
\hline \multicolumn{4}{|l|}{ Stroke } \\
\hline Yes & $11(3.7)$ & $0.68(0.30)$ & 0.009 \\
\hline No & $290(96.3)$ & $0.94(0.32)$ & \\
\hline \multicolumn{4}{|l|}{ Cancer } \\
\hline Yes & $25(8.3)$ & $0.82(0.31)$ & 0.073 \\
\hline No & $276(91.7)$ & $0.94(0.32)$ & \\
\hline \multicolumn{4}{|l|}{ Gout } \\
\hline Yes & $17(5.6)$ & $0.93(0.30)$ & 0.947 \\
\hline No & $284(94.4)$ & $0.93(0.32)$ & \\
\hline \multicolumn{4}{|c|}{ Respiration diseases } \\
\hline Yes & $29(9.6)$ & $0.93(0.28)$ & 0.988 \\
\hline No & $272(90.4)$ & $0.93(0.32)$ & \\
\hline \multicolumn{4}{|c|}{ 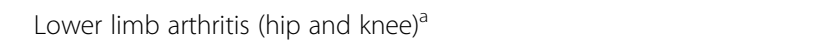 } \\
\hline Yes & $58(19.3)$ & $0.84(0.23)$ & 0.025 \\
\hline No & $240(79.7)$ & $0.95(0.34)$ & \\
\hline \multicolumn{4}{|l|}{ Fall } \\
\hline Yes & $50(16.6)$ & $0.87(0.34)$ & 0.151 \\
\hline No & $251(83.4)$ & $0.94(0.32)$ & \\
\hline \multicolumn{4}{|c|}{ Mental -related comorbid conditions } \\
\hline \multicolumn{4}{|c|}{ Hospital Anxiety and Depression Scale } \\
\hline \multicolumn{4}{|c|}{ Anxiety subscale } \\
\hline$\geq 3$ & $103(34.2)$ & $0.88(0.29)$ & 0.061 \\
\hline$<3$ & $198(65.8)$ & $0.95(0.33)$ & \\
\hline \multicolumn{4}{|c|}{ Depression subscale } \\
\hline$\geq 6$ & $30(10.0)$ & $0.74(0.29)$ & $<0.001$ \\
\hline$<6$ & $271(90.0)$ & $0.95(0.32)$ & \\
\hline
\end{tabular}

${ }^{a}$ Numbers of subjects are not equal to 301 due to missing values in variables 
Table 3 Correlation matrix between 6-M Walking Speed, anthropometric measurement and hand grip strength

\begin{tabular}{|c|c|c|c|c|c|c|c|c|c|c|}
\hline & 1 & 2 & 3 & 4 & 5 & 6 & 7 & 8 & 9 & 10 \\
\hline 1. 6-M Walking Speed (m/sec) & 1 & & & & & & & & & \\
\hline 2. Age (years) & $-0.42^{* * *}$ & 1 & & & & & & & & \\
\hline 3. Height (cm) & $0.32^{* * *}$ & $-0.23^{* * *}$ & 1 & & & & & & & \\
\hline 4. Weight (kg) & $0.12^{*}$ & $-0.21^{* * *}$ & $0.57^{* * *}$ & 1 & & & & & & \\
\hline 5. Body mass index $\left(\mathrm{kg} / \mathrm{m}^{2}\right)$ & -0.10 & -0.09 & -0.07 & $0.78^{* * *}$ & 1 & & & & & \\
\hline 6. Hand grip strength (kg) & $0.47^{* * *}$ & $-0.34^{* * *}$ & $0.65^{* * *}$ & $0.39^{* * *}$ & -0.01 & 1 & & & & \\
\hline 7. Total body muscle mass (kg) & $0.26^{* * *}$ & $-0.22^{* *}$ & $0.85^{* * *}$ & $0.72^{* * *}$ & $0.23^{* *}$ & $0.71^{* * *}$ & 1 & & & \\
\hline 8. Trunk muscle mass (kg) & $0.30^{* * *}$ & $-0.27^{* * *}$ & $0.89^{* * *}$ & $0.65^{* * *}$ & 0.11 & $0.71^{* * *}$ & $0.94^{* * *}$ & 1 & & \\
\hline 9. Upper limbs muscle mass (kg) & $0.24^{* * *}$ & $-0.16^{*}$ & $0.77^{* * *}$ & $0.69^{* * *}$ & $0.25^{* * *}$ & $0.64^{* * *}$ & $0.94^{* * *}$ & $0.87^{* * *}$ & 1 & \\
\hline 10. Lower limbs muscle mass (kg) & $0.20^{* *}$ & $-0.16^{*}$ & $0.72^{* * *}$ & $0.72^{* * *}$ & $0.31^{* * *}$ & $0.62^{* * *}$ & $0.94^{* * *}$ & $0.78^{* * *}$ & $0.89^{* * *}$ & 1 \\
\hline
\end{tabular}

${ }^{*} p<0.05$

$*^{* *} p<0.01$

*** $p<0.001$

model considering all included participants. Hand grip strength $(\beta=0.01$, standard error $[\mathrm{SE}]=0.002, p<0.001$ ) and age $(\beta=-0.15, \mathrm{SE}=0.04, p<0.001)$ were significantly associated with walking speed, but not with sex. After stratification by sex, hand grip strength was associated with walking speed in both men $(\beta=0.01, \mathrm{SE}=$ $0.003, p<0.001)$ and women $(\beta=0.03, \mathrm{SE}=0.006, p<$ 0.001 ), while age was associated with walking speed in only women $(\beta=-0.17, \mathrm{SE}=0.06, p=0.003$ ) (Table 5 ). Accordingly, the association between hand grip strength and walking speed was stable and robust in both sexes.
Therefore, hand grip strength can be used as a proxy for the detection of slow walking speed.

To develop an instrument for detecting slow walking speed, we adopted two strategies. First, we developed a predicted model according to the final models derived from the previous stepwise multiple linear regression model, in which hand grip strength and age were specified to predict walking speed. Furthermore, slow walking speed was identified according to the latest AWGS criteria. Second, because hand grip strength itself is highly correlated with walking speed, we also used the ROC

Table 4 Linear regression analyses for prediction models for the 6-meter walking speed test

\begin{tabular}{|c|c|c|c|c|c|c|}
\hline & \multicolumn{2}{|c|}{ Unadjusted model } & \multicolumn{4}{|c|}{ Stepwise model } \\
\hline & \multirow[b]{2}{*}{ b (se) } & \multirow[b]{2}{*}{$p$} & \multicolumn{2}{|l|}{ Step I } & \multicolumn{2}{|l|}{ Step II } \\
\hline & & & b (se) & $p$ & b (se) & $p$ \\
\hline Age ( $\geq 75$ vs < 75) & $-0.23(0.04)$ & $<0.001$ & & & $-0.15(0.04)$ & $<0.001$ \\
\hline Sex (female vs. male) & $-0.13(0.04)$ & $<0.001$ & & & & \\
\hline Education (primary vs junior and above) & $-0.15(0.04)$ & $<0.001$ & & & & \\
\hline Exercise ( $\geq 3$ / week vs < 3/ week) & $0.17(0.05)$ & $<0.001$ & & & & \\
\hline Height (cm) & $0.01(0.002)$ & $<0.001$ & & & & \\
\hline Weight (kg) & $0.004(0.002)$ & 0.047 & & & & \\
\hline Hand grip strength (kg) & $0.02(0.002)$ & $<0.001$ & $0.02(0.002)$ & $<0.001$ & $0.01(0.002)$ & $<0.001$ \\
\hline Upper limbs muscle mass (kg) & $0.07(0.02)$ & $<0.001$ & & & & \\
\hline Lower limbs muscle mass (kg) & $0.02(0.01)$ & 0.002 & & & & \\
\hline Diabetes mellitus (yes vs. no) & $-0.10(0.05)$ & 0.029 & & & & \\
\hline Hypertension (yes vs. no) & $-0.11(0.04)$ & 0.004 & & & & \\
\hline Heart diseases (yes vs. no) & $-0.12(0.04)$ & 0.004 & & & & \\
\hline Stroke (yes vs. no) & $-0.26(0.10)$ & 0.009 & & & & \\
\hline Lower limb arthritis (yes vs. no) & $-0.11(0.05)$ & 0.025 & & & & \\
\hline Depression (yes vs. no) & $-0.21(0.06)$ & $<0.001$ & & & & \\
\hline Adjusted R-square & & & 0.20 & & 0.24 & \\
\hline
\end{tabular}


Table 5 Stepwise multiple linear regression analyses for prediction models for the 6-meter walking speed test stratified by sex

\begin{tabular}{|c|c|c|c|c|c|c|}
\hline & \multicolumn{4}{|l|}{ Women } & \multirow{2}{*}{\multicolumn{2}{|c|}{$\frac{\text { Men }}{\text { Step I }}$}} \\
\hline & \multicolumn{2}{|l|}{ Step I } & \multicolumn{2}{|l|}{ Step II } & & \\
\hline & b (se) & $p$ & b (se) & $p$ & b (se) & $p$ \\
\hline Age ( $\geq 75$ vs $<75)$ & & & $-0.17(0.06)$ & 0.003 & & \\
\hline \multicolumn{7}{|l|}{ Education } \\
\hline \multicolumn{7}{|l|}{ Exercise } \\
\hline \multicolumn{7}{|l|}{ Height (cm) } \\
\hline \multicolumn{7}{|l|}{ Weight (kg) } \\
\hline Hand grip strength (kg) & $0.04(0.005)$ & $<0.001$ & $0.03(0.006)$ & $<0.001$ & $0.01(0.003)$ & $<0.001$ \\
\hline \multicolumn{7}{|c|}{ Upper limbs muscle mass (kg) } \\
\hline \multicolumn{7}{|c|}{ Lower limbs muscle mass (kg) } \\
\hline \multicolumn{7}{|l|}{ Diabetes mellitus } \\
\hline \multicolumn{7}{|l|}{ Hypertension } \\
\hline \multicolumn{7}{|l|}{ Heart diseases } \\
\hline \multicolumn{7}{|l|}{ Stroke } \\
\hline \multicolumn{7}{|l|}{ Lower limb arthritis } \\
\hline \multicolumn{7}{|l|}{ Depression } \\
\hline Adjusted R-square & 0.27 & & 0.31 & & 0.12 & \\
\hline
\end{tabular}

curve to obtain the optimal cutoff for hand grip strength for detecting slow walking speed. Finally, the performance of these strategies was compared to justify the use of hand grip strength as a single proxy for detecting slow walking speed. The accuracy of the two strategies was comparable (linear prediction model: $68.3 \%$ vs. ROC curve-derived cutoff: $66.9 \%)$. Therefore, we decided to use hand grip strength alone as a proxy for walking speed. To detect slow walking speed, a hand grip strength cutoff value of $19.73 \mathrm{~kg}$ for all participants had a sensitivity of $55 \%$, a specificity of $83 \%$, an AUC of 0.74 , and an accuracy rate of $66.9 \%$. A hand grip strength cutoff value of $35.10 \mathrm{~kg}$ for men had a sensitivity of $92 \%$, a specificity of $42 \%$, an AUC of 0.70 , and an accuracy rate of $66.4 \%$. A hand grip strength cutoff value of $17.93 \mathrm{~kg}$ in women had a sensitivity of $62 \%$, a specificity of $80 \%$, an AUC of 0.76 , and an accuracy rate of $67.9 \%$ (Table 6). An area under the ROC curve of 0.7-0.8 had good diagnostic accuracy [28]. Figure 1 showed the ROC curves for optimal cutoff values of hand grip strength in detecting slow walking speed among total participants and subgroups.

\section{Discussion}

In this study, we found that hand grip strength was significantly associated with walking speed; it was the only variable associated with walking speed in both sexes after considering various sociodemographic, lifestyle, and anthropometric factors in community-dwelling older adults. In addition, we compared the performance of hand grip strength as a single proxy with that of the predicted model in detecting slow walking speed, which showed comparable results. However, a simple cutoff value is more practical in the community. Therefore, we

Table 6 Receiver operating characteristic curve analysis for optimal cutoffs of hand grip strength for detecting slow 6-meter walking speed test

\begin{tabular}{lllllll}
\hline & Hand grip strength $(\mathbf{k g})$ & Sensitivity & Specificity & Area under curve & $\boldsymbol{p}$-value & Accuracy rate $(\%)$ \\
\hline Total & 19.73 & 0.55 & 0.83 & 0.74 & $<0.001$ & 66.9 \\
Men & 35.10 & 0.92 & 0.42 & 0.70 & $<0.001$ & 66.4 \\
Women & 17.93 & 0.62 & 0.80 & 0.76 & $<0.001$ & 67.9 \\
$<75$ years & 23.65 & 0.71 & 0.60 & 0.68 & $<0.001$ & 65.3 \\
$\geq 75$ years & 16.58 & 0.52 & 0.94 & 0.79 & $<0.001$ & 63.3 \\
\hline
\end{tabular}


(A)

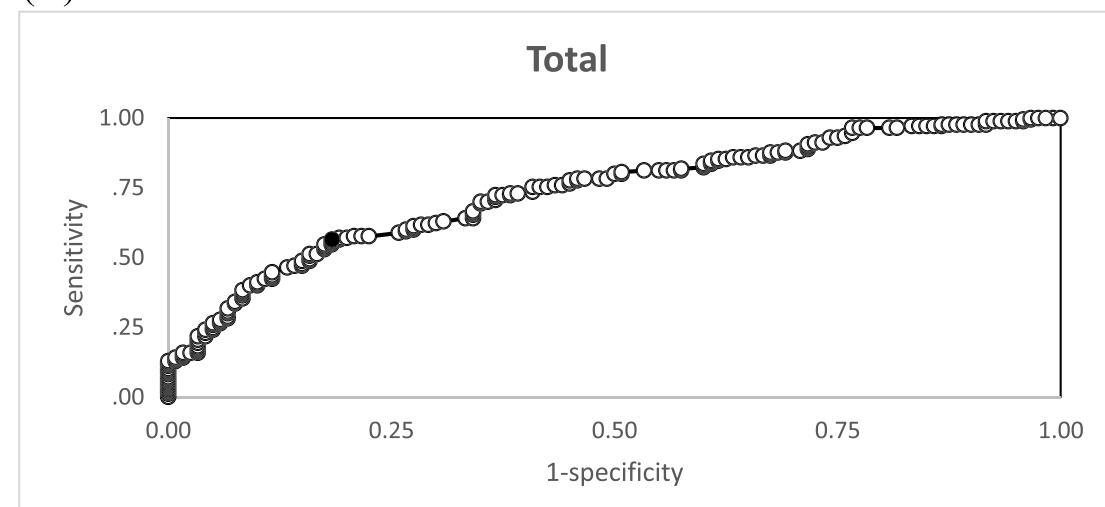

(B)

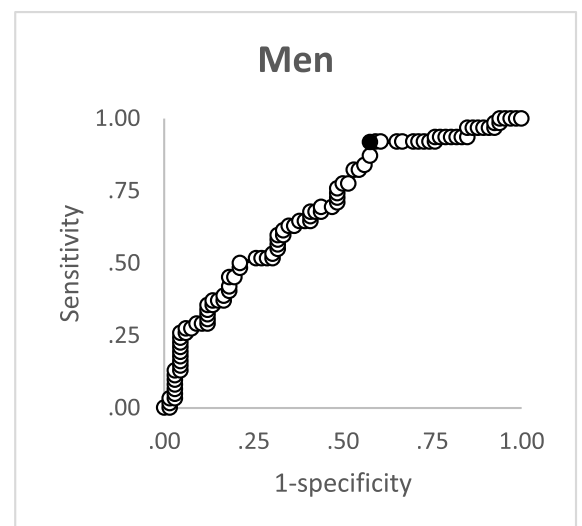

(D)

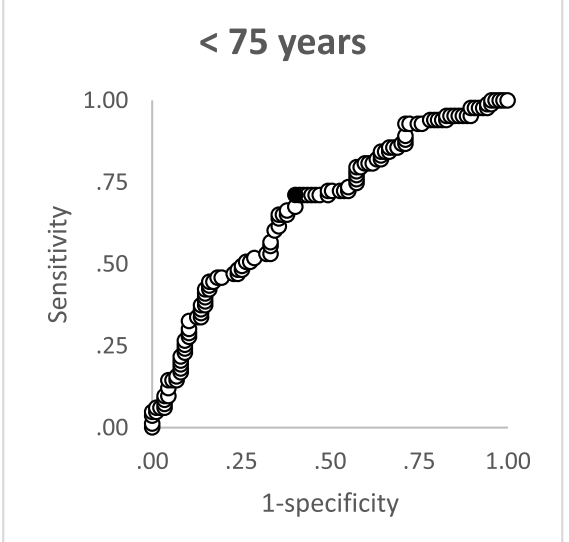

(C)

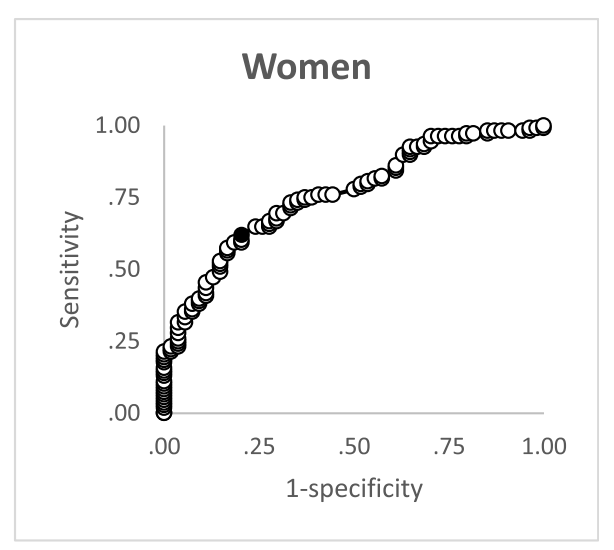

(E)

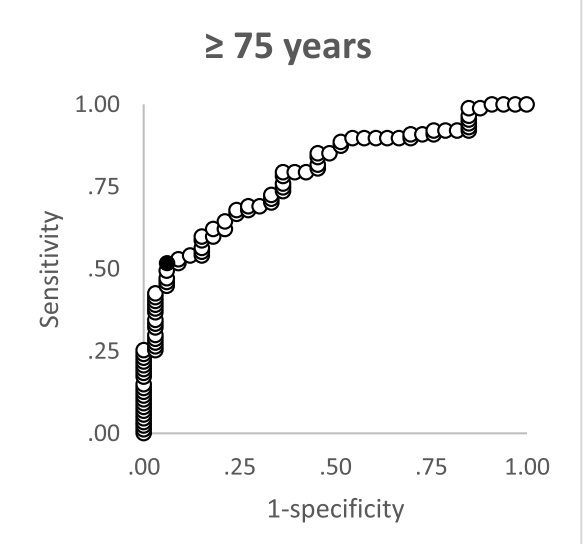

Fig. 1 Receiver operating characteristic curve analysis for optimal cutoff values of hand grip strength in detecting slow walking speed. Panel (A) total participants; Panel (B) men; Panel (C) women; Panel (D) participants aged < 75 years; Panel (E) participants aged $\geq 75$ years. Black point indicates the optimal cutoff point"

decided to use hand grip strength as a single proxy for detecting slow walking speed.

In this study, the mean participant age was 74.3 years and the prevalence of slow walking speed was $56.5 \%$. However, in the Aging Study of Pyeongchang Rural Area (ASPRA) in Korea, the mean age was 76 years and the prevalence of slow walking speed was $78.2 \%$ using a cutoff value of $<1.0 \mathrm{~m} / \mathrm{s}$ [29]. Older mean age of the participants could be an explanation for the higher prevalence reported in the ASPRA. In the Health and Retirement Study conducted in the United States, the mean participant age was 75.4 years and the prevalence of slow 
walking speed was $53.5 \%$ using a cutoff value of < $0.8 \mathrm{~m} / \mathrm{s}$. In our study, if we had used a cutoff value of $<$ $0.8 \mathrm{~m} / \mathrm{s}$, fewer participants would have met the criteria for the slow-walking group, which could have led to underestimation of the prevalence of slow walking speed. Our study echoed the 2019 recommendations of the AWGS, which increased the cutoff of slow walking speed to $<1.0 \mathrm{~m} / \mathrm{s}$. Therefore, our study indicated that it was necessary to determine the optimal cutoff value for hand grip strength based on the most recent definition of slow walking speed. Furthermore, compared with a similar study in the Turkish population, a hand grip strength cutoff value of $32 \mathrm{~kg}$ in men and $22 \mathrm{~kg}$ in women was determined among patients visiting an outpatient clinic [22], while a hand grip strength cutoff value of $35.10 \mathrm{~kg}$ in men and $17.93 \mathrm{~kg}$ in women was implemented among the community-dwelling older adults in our study. Different cutoff values reflect the varying definitions of slow walking speed $(<0.8$ vs. $<$ $1.0 \mathrm{~m} / \mathrm{s}$ ) and differing study design.

In the literature, hand grip strength, lower extremity muscle strength, lower extremity muscle power, and calf muscle area have been used to predict slow walking speed $[24,30]$. Among these, hand grip strength, lower extremity muscle strength, and upper and lower extremity muscle power have shown comparable predictive ability, but not calf muscle area [24, 30]. Our study revealed that muscle mass was not associated with walking speed, which is consistent with the results of a previous study reporting that muscle strength, but not muscle mass, is independently associated with lower extremity performance [31]. These findings support the use of hand grip strength as a proxy for detecting slow walking speed in community-dwelling older adults owing to its accessibility and availability.

This study also provided age- and sex-specific cutoff values for hand grip strength for the detection of slow walking speed. Men and participants aged $<75$ years had higher sensitivity, while women and participants aged $\geq$ 75 years had higher specificity. Therefore, the performance of hand grip strength in detecting slow walking speed differed among subgroups. Our study also showed that the explanatory power of hand grip strength in predicting walking speed was higher in women than in men (adjusted $R^{2}: 0.27$ vs. 0.12). Therefore, hand grip strength could identify slow walking speed better among men and participants aged $<75$ years, while it could identify normal walking speed better among women and participants aged $\geq 75$ years. However, sex was not found to be significantly associated with walking speed in our study. In the ROC analysis, after stratification by sex, the optimal cutoff values for detecting slow walking speed did not notably improve the AUC or accuracy rate. However, the sex-specific cutoff values increased the sensitivity. There is also a trade-off between sensitivity and specificity when cutoffs are assigned to a continuous variable. It should be noted that the AWGS does not recommend sex-specific cutoff values for slow walking speed [13]. In a real-world setting, it may be more convenient and practical to adopt uniform, rather than sexspecific, cutoff values; however, from a prevention and public health perspective, sex-specific cutoff values may identify more individuals who are at risk of slow walking speed. Further investigation is needed to determine whether sex-specific cutoff values are essential.

This study had several strengths. First, using face-toface interviews to obtain information from the participants reduced information bias. Second, various sociodemographic and lifestyle characteristics together with anthropometric measurements were considered in the assessment of the best proxy for the detection of slow walking speed. However, this study also had some limitations. First, participants were limited to communitydwelling older people; therefore, the generalizability of the findings to older people who are institutionalized or who have severe disabilities should be examined further. However, in individuals who are institutionalized or who have severe disabilities, functional decline due to physical conditions or aging tends to be more severe in the lower extremities [32-34]. Muscle strength of the upper extremities, such as hand grip strength, is less affected than that of the lower extremities [32-34]. Second, we used a Camry ${ }^{\circ}$ dynamometer rather than the standard Jamar $^{\circ}$ dynamometer (Jamar, Jackson, MI, USA), because it is cheaper, lighter, and easier to use in the community. Additionally, the Camry dynamometer weighs $1 \mathrm{lbs}$, while the Jamar ${ }^{\circ}$ dynamometer weighs 4 lbs. The Camry ${ }^{\circ}$ dynamometer was validated using the Jamar dynamometer, and a strong correlation was found [15].

\section{Conclusions}

Our study found hand grip strength to be a clinically useful indicator for the detection of slow walking speed, which is detrimental to the health of older adults. Further investigation is warranted to examine the validity of using hand grip strength as a proxy for walking speed to assess frailty.

\section{Abbreviations}

AUC: Area under the curve; AWGS: Asian Working Group for Sarcopenia; ROC: Receiver Operating characteristic; SE: Standard error

\section{Acknowledgements}

The authors would also like to thank Yang-Ming Crusaders, Mr. Da-Wei Lin, Ms. Yu-Hui Lin, Mr. Chia-Hsiang Lin, and Ms. Tzu-Chun Lo for their help with data collection.

\section{Authors' contributions}

Yen-Huai Lin and Hsi-Chung Chen initiated the study; all authors contributed to the study design. Yen-Huai Lin, Hsi-Chung Chen, and Nai-Wei Hsu 
managed the data collection, performed data analysis, and wrote the first draft of the manuscript. Yen-Huai Lin, Nai-Wei Hsu, Hsi-Chung Chen, and Pesus Chou are collectively responsible for interpreting the results and critically reviewing the subsequent drafts of the manuscript. All authors have read and approved the final manuscript.

\section{Funding}

This work was supported by grants from the Ministry of Science and Technology, Taiwan (MOST 108-2314-B-002 -110 -MY2) and the National Taiwan University Hospital (UN110-021).

\section{Availability of data and materials}

The datasets used and analyzed during the current study are available from the corresponding author on reasonable request.

\section{Declarations}

\section{Ethics approval and consent to participate}

This study was approved by the institutional review board (IRB) of NYMUH (IRB No. 2011A016). Written informed consent was obtained from all participants. All methods were performed in accordance with the relevant guidelines and regulations.

\section{Consent for publication}

Not Applicable.

\section{Competing interests}

The authors declare that they have no competing interests.

\section{Author details}

'Department of Medical Imaging, Cheng Hsin General Hospital, Taipei, Taiwan. ${ }^{2}$ Department of Medicine, School of Medicine, National Yang Ming Chiao Tung University, Taipei, Taiwan. ${ }^{3}$ Department of Psychiatry and Center of Sleep Disorders, National Taiwan University Hospital, Taipei, Taiwan. ${ }^{4}$ Community Medicine Research Center, National Yang Ming Chiao Tung University, Taipei, Taiwan. ${ }^{5}$ Division of Cardiology, Department of Internal Medicine, National Yang Ming Chiao Tung University Hospital, 152 Hsing-Ming Road, 26042 Yilan, Taiwan. 'Public Health Bureau, Yilan County, Taiwan.

\section{Received: 10 March 2021 Accepted: 28 June 2021}

\section{Published online: 16 July 2021}

\section{References}

1. Sternberg SA, Wershof Schwartz A, Karunananthan S, Bergman H, Mark Clarfield A. The identification of frailty: a systematic literature review. J Am Geriatr Soc. 2011:59(11):2129-38.

2. Fried LP, Ferrucci L, Darer J, Williamson JD, Anderson G. Untangling the concepts of disability, frailty, and comorbidity: implications for improved targeting and care. J Gerontol A Biol Sci Med Sci. 2004;59(3):255-63.

3. Lahousse L, Maes B, Ziere G, Loth DW, Verlinden VJ, Zillikens MC, Uitterlinden AG, Rivadeneira F, Tiemeier $\mathrm{H}$, Franco $\mathrm{OH}$, et al. Adverse outcomes of frailty in the elderly: the Rotterdam Study. Eur J Epidemiol. 2014:29(6):419-27.

4. Fried LP, Tangen CM, Walston J, Newman AB, Hirsch C, Gottdiener J, Seeman T, Tracy R, Kop WJ, Burke G, et al. Frailty in older adults: evidence for a phenotype. J Gerontol A Biol Sci Med Sci. 2001;56(3):M146-156.

5. Liang-Ju Chen C-YC, Lue Bee-Horng, Tseng Ming-Yueh, Wu Shwu-Chong Prevalence and Associated Factors of Frailty Among Elderly People in Taiwan. Int J Gerontol. 2014;8(3):114-9.

6. Cruz-Jimenez M. Normal Changes in Gait and Mobility Problems in the Elderly. Phys Med Rehabil Clin N Am. 2017;28(4):713-25.

7. Guralnik JM, Ferrucci L, Pieper CF, Leveille SG, Markides KS, Ostir GV, Studenski S, Berkman LF, Wallace RB. Lower extremity function and subsequent disability: consistency across studies, predictive models, and value of gait speed alone compared with the short physical performance battery. J Gerontol A Biol Sci Med Sci. 2000;55(4):M221-231.

8. Studenski S, Perera S, Patel K, Rosano C, Faulkner K, Inzitari M, Brach J, Chandler J, Cawthon P. Connor EB, et al. Gait speed and survival in older adults. JAMA. 2011;305(1):50-8.
9. Watson NL, Rosano C, Boudreau RM, Simonsick EM, Ferrucci L, Sutton-Tyrrell K, Hardy SE, Atkinson HH, Yaffe K, Satterfield S, et al. Executive function, memory, and gait speed decline in well-functioning older adults. J Gerontol A Biol Sci Med Sci. 2010;65(10):1093-100.

10. Cruz-Jentoft AJ, Bahat G, Bauer J, Boirie Y, Bruyere O, Cederholm T, Cooper C, Landi F, Rolland Y, Sayer AA, et al. Sarcopenia: revised European consensus on definition and diagnosis. Age Ageing. 2019;48(1):16-31.

11. Clegg A, Rogers $L$, Young J. Diagnostic test accuracy of simple instruments for identifying frailty in community-dwelling older people: a systematic review. Age Ageing. 2015;44(1):148-52.

12. Vermeulen J, Neyens JC, van Rossum E, Spreeuwenberg MD, de Witte LP. Predicting ADL disability in community-dwelling elderly people using physical frailty indicators: a systematic review. BMC Geriatr. 2011; 11:33

13. Chen LK, Woo J, Assantachai P, Auyeung TW, Chou MY, lijima K, Jang HC, Kang L, Kim M, Kim S, et al. Asian Working Group for Sarcopenia: 2019 Consensus Update on Sarcopenia Diagnosis and Treatment. J Am Med Dir Assoc. 2020;21(3):300-307.e302.

14. Li YZ, Zhuang HF, Cai SQ, Lin CK, Wang PW, Yan LS, Lin JK, Yu HM. Low Grip Strength is a Strong Risk Factor of Osteoporosis in Postmenopausal Women. Orthop Surg. 2018;10(1):17-22.

15. Lin YH, Chen HC, Hsu NW, Chou P, Teng MMH. Hand grip strength in predicting the risk of osteoporosis in Asian adults. J Bone Miner Metab. 2021;39(2):289-294

16. Zhang XS, Liu YH, Zhang Y, Xu Q, Yu XM, Yang XY, Liu Z, Li HZ, Li F, Xue CY. Handgrip Strength as a Predictor of Nutritional Status in Chinese Elderly Inpatients at Hospital Admission. Biomed Environ Sci. 2017:30(11):802-10.

17. Kobayashi-Cuya KE, Sakurai R, Suzuki H, Ogawa S, Takebayashi T, Fujiwara Y. Observational Evidence of the Association Between Handgrip Strength, Hand Dexterity, and Cognitive Performance in Community-Dwelling Older Adults: A Systematic Review. J Epidemiol. 2018;28(9):373-81.

18. Cheung CL, Nguyen US, Au E, Tan KC, Kung AW. Association of handgrip strength with chronic diseases and multimorbidity: a cross-sectional study. Age (Dordr). 2013;35(3):929-41.

19. Ashdown-Franks G, Stubbs B, Koyanagi A, Schuch F, Firth J, Veronese N, Vancampfort D. Handgrip strength and depression among 34,129 adults aged 50 years and older in six low- and middle-income countries. J Affect Disord. 2019:243:448-54.

20. Chen HC, Hsu NW, Chou P: The Association Between Sleep Duration and Hand Grip Strength in Community-Dwelling Older Adults: The Yilan Study, Taiwan. Sleep 2017; 40(4):zsx021.

21. Alley DE, Shardell MD, Peters KW, McLean RR, Dam TT, Kenny AM, Fragala MS, Harris TB, Kiel DP, Guralnik JM, et al. Grip strength cutpoints for the identification of clinically relevant weakness. J Gerontol A Biol Sci Med Sci. 2014;69(5):559-66.

22. Bahat G, Tufan A, Tufan F, Kilic C, Akpinar TS, Kose M, Erten N, Karan MA, Cruz-Jentoft AJ. Cut-off points to identify sarcopenia according to European Working Group on Sarcopenia in Older People (EWGSOP) definition. Clin Nutr. 2016:35(6):1557-63.

23. Duchowny KA, Peterson MD, Clarke PJ. Cut Points for Clinical Muscle Weakness Among Older Americans. Am J Prev Med. 2017;53(1):63-9.

24. Lauretani F, Russo CR, Bandinelli S, Bartali B, Cavazzini C, Di lorio A, Corsi AM, Rantanen T, Guralnik JM, Ferrucci L. Age-associated changes in skeletal muscles and their effect on mobility: an operational diagnosis of sarcopenia. J Appl Physiol. 2003;95(5):1851-60.

25. Delinocente MLB, de Carvalho DHT, Máximo RO, Chagas MHN, Santos JLF, Duarte YAO, Steptoe A, de Oliveira C, Alexandre TDS. Accuracy of different handgrip values to identify mobility limitation in older adults. Arch Gerontol Geriatr. 2021;94:104347.

26. Hsu NW, Tsao HM, Chen HC, Chou P. Anxiety and depression mediate the health-related quality of life differently in patients with cardiovascular disease and stroke-preliminary report of the Yilan study: a population-based community health survey. PloS one. 2014;9(9):e107609.

27. Leung $\mathrm{CM}$, Ho S, Kan CS, Hung CH, Chen CN. Evaluation of the Chinese version of the Hospital Anxiety and Depression Scale. A cross-cultural perspective. Int J Psychosom. 1993;40(1-4):29-34.

28. Šimundić AM. Measures of diagnostic accuracy: basic definitions. EJIFCC. 2009:19(4):203-11.

29. Jung HW, Jang IY, Lee CK, Yu SS, Hwang JK, Jeon C, Lee YS, Lee E: Usual gait speed is associated with frailty status, institutionalization, and mortality in community-dwelling rural older adults: a longitudinal 
analysis of the Aging Study of Pyeongchang Rural Area. Clin Interv Aging. 2018;13:1079-1089.

30. Ramírez-Vélez R, Sáez de Asteasu ML, Martínez-Velilla N, Zambom-Ferraresi F, García-Hermoso A, Izquierdo M: Handgrip Strength as a Complementary Test for Mobility Limitations Assessment in Acutely Hospitalized Oldest Old. Rejuvenation Res. 2021;24(3):213-219.

31. Visser M, Newman AB, Nevitt MC, Kritchevsky SB, Stamm EB, Goodpaster BH, Harris TB. Reexamining the sarcopenia hypothesis. Muscle mass versus muscle strength. Health, Aging, and Body Composition Study Research Group. Ann N Y Acad Sci. 2000;904:456-61.

32. Amaral JF, Alvim FC, Castro EA, Doimo LA, Silva MV, Novo Júnior JM. Influence of aging on isometric muscle strength, fat-free mass and electromyographic signal power of the upper and lower limbs in women. Braz J Phys Ther. 2014;18(2):183-90.

33. Hicks GE, Shardell M, Alley DE, Miller RR, Bandinelli S, Guralnik J, Lauretani F, Simonsick EM, Ferrucci L. Absolute strength and loss of strength as predictors of mobility decline in older adults: the InCHIANTI study. J Gerontol A Biol Sci Med Sci. 2012;67(1):66-73.

34. Ferrreira L, Gobbi $\mathrm{S}$, Gobbi LT. An explanatory mechanism for the different decline in limb strength in older women. Arch Gerontol Geriatr. 2009;49(3): 373-7.

\section{Publisher's Note}

Springer Nature remains neutral with regard to jurisdictional claims in published maps and institutional affiliations.

Ready to submit your research? Choose BMC and benefit from:

- fast, convenient online submission

- thorough peer review by experienced researchers in your field

- rapid publication on acceptance

- support for research data, including large and complex data types

- gold Open Access which fosters wider collaboration and increased citations

- maximum visibility for your research: over $100 \mathrm{M}$ website views per year

At $\mathrm{BMC}$, research is always in progress.

Learn more biomedcentral.com/submissions 